\title{
Obstacles of Organizational Learning and Self-transcendence: Theoretical Research Based on Chinese Family Business
}

\author{
Mengyun $\mathrm{Wu}^{1}$ \& Chuanming $\mathrm{Chen}^{2}$ \\ ${ }^{1}$ School of Finance \& Economics, Jiangsu University, Zhenjiang, China \\ ${ }^{2}$ Business School, Nanjing University, Nanjing, China \\ Correspondence: Mengyun Wu, School of Finance \& Economics, Jiangsu University, Zhenjiang, China. E-mail: \\ mewu@ujs.edu.cn
}

$\begin{aligned} & \text { Received: June 5, } 2012 \quad \text { Accepted: July 5, } 2012 \quad \text { Online Published: October 18, } 2012 \\ & \text { doi:10.5539/ass.v8n13p89 }\end{aligned} \quad$ URL: http://dx.doi.org/10.5539/ass.v8n13p89

This research is supported by National Natural Science Fund (71102160), Humanities and Social Sciences Project of Ministry of Education (10YJC630281), National Statistics Fund (2011LY053), Philosophy \& Social Science Project of Jiangsu Province (09SJB630014\&2010SJB630014) \& Advanced Talent Project of Jiangsu University (09JDG050)

\begin{abstract}
Family enterprises widely exist in countries of the world. No matter in quantity or in scale, family enterprise takes a great share of world economy and occupies a very important position in national economy. Nowadays, research on family enterprise turns to be the focus of theoretic research in all countries, and organizational learning is also thought to be the key issue of family enterprises to survive, develop and maintain competitive advantages. However, the obstacles in learning are difficult questions and may weaken family enterprises' core competence. Thus, the article starts with the basic meaning of obstacles in organizational learning, analyzes their influence factors from several aspects (learning process, organization's ideas and culture), and puts forward the countermeasures for enhancing organizational learning ability of family enterprises.
\end{abstract}

Keywords: organizational learning, obstacles in learning, culture, leadership, learning framework

\section{Introduction}

Since Cyert \& March (1963) firstly drew out the meaning of learning organization, many scholars give broad review on the research on organizational learning, Argyris \& Schon (1978) wrote the book titled Organizational Learning: a Theory of Action Perspective, as one hot pot of western organizational behavior study, organizational learning not only develops more systematic theories, but also sets a series of effective techniques and methods. Huber (1991) concludes that research has not been able to create any guidelines to increase the effectiveness of organizational learning; Peter Senge (1999) says in The Fifth Discipline that enterprises' only lasting advantage in the future is to see whether they have capacity to learn faster than their competitors. Many other researchers have expressed their frustration on the fragmented state of the theory and the lack of practical value of the results of research on organizational learning (Pentland, 1995; Jones, 1995; Hendry, 1996; Tsang, 1997), and there are so many scholars also believe that the organizational learning of enterprise is a capability which embodies in the products and services.

Organizations are increasingly paying attention to the concept of organizational learning in order to increase competitive advantage, innovation and effectiveness. In the time of knowledge-based economy, more and more family-businesses actively promote organizational learning plans, which are driven by the following issues: firstly, the current knowledge innovation and networking are profoundly changing the internal conditions and external environment. Enterprises must cultivate organizational learning capacity and respond rapidly to the changes of environment (Bisel, 2012); secondly, enterprise managers or employees are increasing dissatisfied with the order-control mode under traditional hierarchy. More and more enterprises operate well under the humanistic philosophy (Porth, Bausch \& Mccall, 1999); thirdly, since knowledge gradually become a major source of competitive advantage, enterprises mainly obtain competitive advantages through knowledge, which is the most direct source of learning and could be cumulative, conversed, created and form a knowledge-based 
competitive advantage (Templeton \& Snyder, 1999; Crossan, 2011); and lastly, because of problems such as aging or vision-driven, organization would like to explore ways to promote organizational change (Senge, et al, 1999).

\section{Organizational Learning of Family Enterprises: An Interesting Study}

Organizational learning is a multifaceted and multiphased phenomenon, a complex interplay between different elements of a system. It cannot be studied by reducing the scope to one or another element, but a minimal meaningful system as a whole should be taken as the unit of analysis and intervention. The concept of a learning organization has to be more and more popular since organizations want to be changeable. Learning is a dynamic concept and it emphasizes the nature of organizations.

Organizational learning has some special significance to Chinese family enterprises. Firstly, the organizational culture can be regarded as common knowledge embodiment within the organization and the management of enterprises to the release internal resources. By reducing internal friction and conflict, it will improve organizational stability and enhance the operational efficiency of organizations; Secondly, organizational learning is values of understanding based on the organizational strategy, staff will develop loyalty to the organization rather than to the business owner or a certain supervisor; most importantly, organizational learning is the cognitive mechanism to ensuring cooperative behaviors will occur in the absence of interpersonal relationships, it can help enterprises to establish a family trust which transcends personal and emotional relationships. It will breakthrough the bottleneck of social trust constraints, effectively absorb resources and promote transmission of individual knowledge and skills within the scope of the organization. Meanwhile, organizational learning is the complex internal resource, which is not easy to imitate and may become a source of competitive advantage. Therefore, the organizational learning in China will create an effective means of competitive advantage and become the key endogenous factors to family business growth.

\subsection{Knowledge Acquisition}

Learning occurs when an organization acquires knowledge. Declarative knowledge or information is acquired by adapting to environment, using information systems and bibliometrics (Dodgson, 1993). Learning occurs not only because of knowledge acquisition from outside the inside of the organization but also because of rearrangement of existed knowledge and revision of theories.

\subsection{Information Distribution}

Information distribution refers to the process by which an organization shares information among its units and members, thereby promoting learning and producing new knowledge or understanding. In the form of tacit know-how, letters, memos, informal conversations and reports, knowledge is captured and distributed. Brown and Duguid (1991) contend that lots of learning and innovation take place in informal "communities of practice". Also, greater sharing or distribution of information leads to greater organizational learning.

\subsection{Information Interpretation}

In order to be shared, information must be interpreted. Information interpretation is the process by which distributed information gives one or more commonly understood meanings. The formation of meaning which is called procedural knowledge states that individuals and groups have prior belief structures (Dodgson, 1993; Huber, 1991). These belief structures are stored as a rule-base or a profile, which is automatically applied to any incoming information in order to form a meaningful knowledge that can be stored. The interaction between stored mental models and interpretation is critical to understanding how organizations learn. Greater learning occurs when more and more varied interpretations are developed.

\subsection{Organizational Memory}

Organizational memory refers to the repository where knowledge is stored for future use. It also called "corporate knowledge" or "corporate genetics". Decision makers store and retrieve not only hard data or information but also "soft" information. This soft or interpreted information could be in the form of tacit know-how, expertise, biases, experiences, lists of contacts, anecdotes, etc. Organizational memory plays a very critical role in organizational learning. Both the demonstratability and usability of learning depend on the effectiveness of the organization's memory. The major challenge for organizations exists in interpreting information and creating organizational memory that is easily accessible.

\section{Obstacles and Fact Analysis of Family Business' Institutional Learning}

All kinds of literature about organizational learning stress that study is an experience to gain a competitive advantage, and that organizational learning is a natural and continuously advancing process, but in fact, 
organizational learning is neither a process without effort, nor an automatic process. As media reports that there are obstacles of organizational learning, and organizational learning disabilities will transmit to the new members of a group or organization due to the dynamic and complex nature. Organizational learning obstacles are factors that impede the learning process in organizations, to which Senge (1990) called "learning disabilities"; McGill (1992) called "learning deviation" and Snyder \& Cummings (1998) referred to as "learning deviation". At present, related literature can be divided into three areas: the disruption of organizational learning process, the psychological and cultural learning barriers as well as the obstacles of organizational structure and leadership.

\subsection{Interruption of Organizational Learning Process}

The four-phase model includes the four process: discovery - invention - production -categories, that is, the members of the organization will find errors in the comparison other organizations (finding); diagnosis to the reasons of gap, and to develop appropriate solutions to reduce the gap (invention), and then lead to action, and record the results (production), take actions and apply to similar situations (category). Nonaka \& Takeuchi (1992) divide knowledge into tacit knowledge and explicit knowledge, and put forward a four-stage model: I , sharing tacit knowledge among persons, and tacit knowledge sharing in the team after being converted into explicit knowledge (externalize); II, various members of the team will integrate common knowledge systems into new knowledge (combines); III, through studying the new knowledge, the members of the organization translate them into their own, and complete knowledge proliferation (internalization); IV, members of the organization who have different tacit knowledge affect each other (socialization). Thus, a process of organizational learning ends. On the basis of above analysis, March \& Olsen (1975) analyze the interrupted type of organizational learning process, and Edgar (2004) integrates single cognitive style and institutional cognitive style, listed as bellows (figure 1):

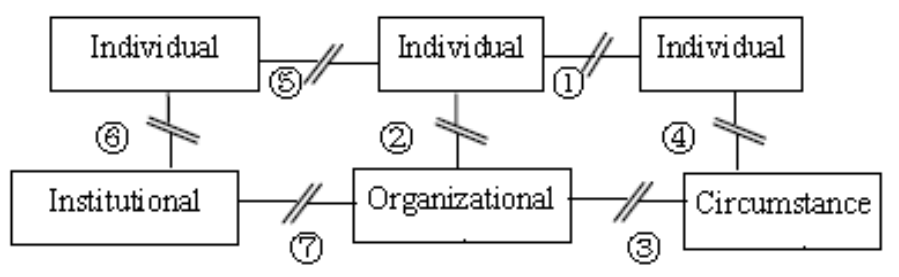

Figure 1. Interruption of organizational learning process

Related obstacles factors include: (1) restricted study: Persons cannot apply what they have learned, and interruption occurs between beliefs and action; (2) audience learning: personal behavior change, but can not convince other people or members; (3) superstition learning: the knowledge among members of organization may not effectively diffuse; (4) fuzzy learning: individual learning recognition can not lead to environmental changes and associated interruption; (5) situated learning: individual learning has been forgotten, or have not been using; (6) fragment learning: the organization cannot change the cognitive style; (7) opportunity learning: Organization would circumvent the standards process, and result in inconsistent between organizational actions and cognitive patterns.

\subsection{Obstacles Relating to Organizational Structure and Leadership}

Similar to psychology of organizational learning, organizational culture embedded in the organizational strategy and structure is difficult to change. Organization is not a monolithic culture, which is often constituted by sub-culture; this sub-culture develops in the organizational units, sectors, and levels. If members of the culture do not understand each other's terminology, metaphor or story, organizational culture and the spirit of the learning map rooted in the past will hinder the further learning. Smith (2012) further pointed out that the tacit assumption constituting an organizational culture will impede organizational learning, listed as follows: (1) mistake and intolerance; (2) members in the course of exchange disingenuous; (3) unequal status of organizational learning process; (4) neglect to learning.

\subsection{Psychological and Cultural Barriers of Organizational Learning}

The centralization and decentralization of organizational structure are closely related to the leadership of enterprises. Therefore, the leadership of the enterprise organization is also considered an important factor. In response to what the leadership is, Drucker (2004) said, "Leadership is prospect". Indeed, the leadership determines the future, but at the same time, the leadership also contains a vision other than power, that is, a learning and innovation tension. As the former GE chairman Jack Welch said, leaders should be the "real engine, 
and make learning, sharing and seeking the blood of business". The corporation's leadership and organizational ability are closely related, and when the leader's behaviors do not conducive to learning, organizational learning will be impeded; secondly, organization will gradually develop the cultural, and NIH (no innovation here) will become a popular vocabulary, organizational learning capacity will be low, let learning "lying there" and prone to inertia and paranoia.

\section{Transcending Obstacles of Organizational Learning and Creating Knowledge}

We believe that obstacles of organizational learning are not isolated factors, and need to interrelate in a complete organizational learning framework (including leadership, organizational culture, learning ability of members, etc.) At the same time, the most effective way of exploring learning disability should be approached form way of leadership: firstly, it is relatively independent, and the most easily enhancing resources; Secondly, only through the exercise of the functions of leadership at all levels, the deeper obstacles can be surpassed.

\subsection{Building Team Leadership and Upgrading Leadership Capacity}

In the time of knowledge-based economy, leadership of enterprises is not initiated by centralization, but by top-to-bottom equal spirit of cooperation. Nowadays, centralization and vertical hierarchy of organizations converse to authorize and flat organic structure, that is to say, the organizational leadership will promote the development of enterprises. We should be more concerned about the strategic and goal-oriented enterprises; the concentric circles of personal "weak governance" organizations may gain "strong governance" leadership. The team leadership of organizational learning have enormous supporting role and create a learning organization, it can pass concepts, information and the separation of powers to subordinate staff, stimulate their learning ability, and cultivate their potential leadership. Organizational members will create the atmosphere of mutual trust and a mechanism for enhancing learning. It is worth mentioning that in the era of knowledge-based economy, the form of virtual enterprises and strategic alliances gradually arise, the cultivation of team leadership of corporations has not been strict to the company's internal talent, but to the progressive development of the company in the chain of the external value, so as to make every aspects of the value chain have strong combat effectiveness.

\subsection{Effective Integration of Organizational Structure and Learning Network}

As mentioned above, learning organization does not have a standard uniform or model, the members of enterprise organization need construct certain types of structure to meeting the needs of their own learning network, and enhance the competitiveness of enterprises through the fitness of organizational structure and organizational learning network. As enterprises' structure is increasingly flat and virtual, the more perfect learning network will be more understanding, and the development of all the different types of expertise tools, methods and theories will be helpful to develop enterprises best practices.

\subsection{Innovation of Organizational Learning Culture}

In today's society, the Internet changes everything, successful enterprises would adapt to the differences and collisions of cultures, languages, political and economic perspective, work and learning methods. It is necessary to establish a global study of corporate culture. Therefore, organizational learning culture will become one of the most important parts of the organizational culture, which is differ from the traditional culture: Firstly, it is a culture of trust, openness and equality, with the initiative, conscious participation to achieve organizational learning and exchanges; Secondly, it is the culture of sharing knowledge, and the way of changing tacit knowledge to dominant, it restricts knowledge generation and sharing, and also relates to knowledge management and effectiveness of the Organization's core competitiveness; Thirdly, it is the culture of unifying the values of organization, individuals and organizations are honest in mutual treatment, discuss openly and with no reservations, knowledge and information can move freely in a broader scope.

\subsection{Construction of a New Organizational Learning Framework}

The article holds that the aforementioned organizational learning process models have inherent shortcomings, organizational learning does not reflect the integrity of the dynamic characteristics: Firstly, they do not reflect the whole process of organizational learning - the lacking of feedback; Secondly, they do not reflect the dynamics of organizational learning's spiral rising and accumulating process. Therefore, there are worth referring views from domestic scholars, and paper presents a new type of organizational learning architecture (as shown in Figure 2). 


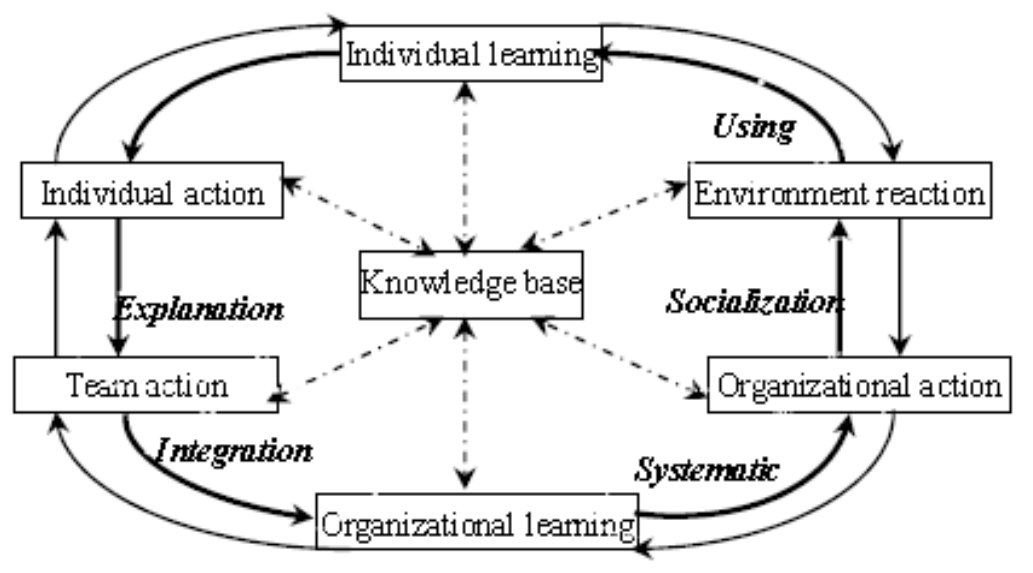

Feed forward

Feedback

Knowledge flow

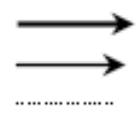

Figure 2. New framework of organizational learning

Organizational learning in the era of knowledge economy should be a new dynamic process, not only occurs with the time passing, but also creates a tension between exploring new study and utilizing existing learning; the former is a kind of feed-forward process, while the latter is a kind of feedback. In the process of feed-forward, people aware of experience and possible existence (intuition), then individuals will take actions through language (operation) and will explain ideas perceived (explanation or interpretation). After the team members begin to reach a consensus and take concerted actions (integration), mechanism is the learning process of feedback, that is, the new study will be institutional and informal practices and will be systematically collected, stored, transmitted, analyzed and used, so as to form a cycle of progressive learning process.

If we say that feed-forward is the process of producing knowledge, feedback is process of applying knowledge, and knowledge base covers the accumulation of knowledge and organizational learning spiral. Organizational learning is one of the most important impact factors of knowledge flows in the knowledge base. It also changes the quality and quantity of knowledge stock. Organization and the knowledge base connect each other through two-way arrows, each stage can generate new knowledge and deposit to the base. In a word, effective process of organizational learning will be able to increase process of feed forward and feedback, improve the intuition, interpretation, integration and effective system among the individuals, groups and organizations to achieve two-way flow. At the same time, it can also be a conscious decision to learn how to learn, to find ways of improving the efficiency of learning and reflection to perfect integration, and carry out the effective implementation of knowledge management and knowledge innovation.

\section{Conclusions}

Organizational learning occurs due to the interplay of various factors such as structure, strategy, environment, technology, and culture. In this paper, we briefly reviewed some of the theoretical concepts related to learning without going into much detail about the various determinants and outcomes. We have not discussed details about how organizational learning can bring about change and increase effectiveness in organizations. More and more organizations have realized that in order to be successful in a highly competitive environment, they must encourage double-loop and deuteron learning. The implications of not becoming a learning organization can be costly.

Processes of knowledge acquisition, information distribution, information interpretation, and organizational memory are complex. With the displacement of people due to downsizing efforts, organizations are discharging vast amounts of organizational knowledge without realizing the long-term implications of such short-term actions. The only way organizations can preserve knowledge and further promote organizational learning is to use information systems to store and retrieve such collective knowledge. In this paper, we reviewed some of the potential impacts of information systems on organizational leaning. As mentioned earlier, very little work has been done in this area and there is general agreement among researchers that organization theorists and information systems researchers need to come together to explore this topic further. 
Information systems developers should focus on how systems can support the central features of work practice such as narration, collaboration, and social construction. As applications are developed, studies also need to be conducted to evaluate the effectiveness of such information systems in promoting organizational learning. Learning is important for organizations to survive and sustain competitive advantage and promote innovation. Information systems can enable this survival strategy, the innovative spirit, and the competitive edge.

Learning organizations will treat competition more as a means of learning than a hostile force. Competition enables organizations to compare their own performance with others in the industry and learn from that exercise. Learning must occur within the organization as a result of the firm's interaction with the environment and this can be achieved through information processing. Information processing reduces uncertainty and hence increases teach (Dirks, 2001). Organizations scan the environment and acquire information through "information brokers" or "boundary spanners". These individuals facilitate exploration and exploitation by carrying out sense-making and interpreting activities. Learning ability has been the most critical components of core competencies system in the modern knowledge-intensive enterprises, and enterprises' competitiveness is no longer comes from the financial capital, but from the competitions among organizational innovations, organizational learning and the reaction speed. If enterprises wish to fully integrate into the global competitive environment, there is the only strategy: learning, innovation, and re-learning. The most important strategic value of organizational learning is to surpassing learning barriers, creating new knowledge and building self-adapt and innovative learning organization. It is organizational learning's profound sense of reality (Kleiner, 2012).

\section{References}

Bisel, R. S., Messersmith, A. S., \& Kelley, K. M. (2012). Supervisor-Subordinate Communication: Hierarchical Mum Effect Meets Organizational Learning. Journal of Business Communication, 49(2), 128-147. http://dx.doi.org/10.1177/0021943612436972

Cheng, B., Wang, M., \& Moormann, J. (2012). The Effects of Organizational Learning Environment Factors on $\begin{array}{lllll}\text { E-Learning Acceptance. } \quad \text { Computers \& } & \text { Education, } & \text { 58(3), } & \text { 8999. }\end{array}$ http://dx.doi.org/10.1016/j.compedu.2011.10.014

Crossan, M. M., Maurer, C. C., \& White, R. E. (2011). Reflections on the 2009 AMR Decade Award: Do We have a Theory of Organizational Learning?. Academy of Management Review, 36(3), 446-460. http://dx.doi.org/10.5465/AMR.2011.61031806

Dirks. (2001). Organizational learning and knowledge innovation. Shanghai: Shanghai People's Publishing House.

Edgar, H. S. (2004). Organizational Culture and Leadership (3rd ed.). London: Jossey-Bass Publishers.

Kleiner, M. M., Nickelsburg, J., \& Pilarski, A. M. (2012). Organizational and Individual Learning and Forgetting. Industrial \& Labor Relations Review, 65(1), 68-81.

Kumar, K., Ram, S., \& Charles, Y. (1998). Examining the Market Orientation-Performance Relationship: A Context-Specific Study. Journal of Management, 24(2), 201-233.

Mason, R. M. (1993). Strategic information systems: Use of information technology in a learning organization. Proceedings of the Twenty-Sixth Hawaii International Conference on System Sciences '93, CA: IEEE Press, 840-849. http://dx.doi.org/10.1109/HICSS.1993.284272

Senge, P. M. (1990). The Fifth Discipline. New York: Doubleday.

Smith, P. A. C. (2012). The Importance of Organizational Learning for Organizational Sustainability. Learning Organization, 19(1), 4-10. http://dx.doi.org/10.1108/09696471211199285 